\title{
Deproteinized Natural Rubber Grafted with Polyacrylonitrile (PAN)/Polystirene (PS) and Degradation of its Mechanical Properties by Dimethyl Ether
}

\author{
Tuti Indah Sari ${ }^{*}$, Asep Handaya Saputra², Setijo Bismo², Dadi R. Maspanger ${ }^{3}$ \\ ${ }^{1}$ Department of Chemical Engineering, Faculty of Engineering, Sriwijaya University, Kampus Indralaya, \\ Indralaya 30662, Indonesia \\ ${ }^{2}$ Department of Chemical Engineering, Faculty of Engineering, Universitas Indonesia, Kampus UI Depok, Depok \\ 16424, Indonesia \\ ${ }^{3}$ Indonesian Rubber Research Institute, Jl. Salak Bogor 16151, Indonesia
}

\begin{abstract}
Dimethyl ether (DME) is a clean fuel that has moderate polarity, swells easily, and dissolves organic compounds. It has the ability to attack some sealing materials and plastic components because of its low viscosity. The modification of deproteinized natural rubber with acrylonitrile (AN) monomer and styrene (ST) monomer by an emulsion copolymerization process can be used to obtain DPNR-g-PAN/PS copolymers. This process uses a stirred reactor with $\mathrm{T}=65^{\circ} \mathrm{C}$, $\mathrm{P}=1 \mathrm{~atm}$, initiator potassium persulfate $\left(\mathrm{K}_{2} \mathrm{~S}_{2} \mathrm{O}_{8}\right)$, and an emulsifier sodium dodecyl sulfate (SDS). The copolymer DPNR-g-PAN/PS can be used to seal storage for DME because it is expected to reduce the degradation of rubber due to the presence of DME. The parameters that were used in testing for the resistance of DPNR included swelling, shrinking, the infrared spectrum obtained through Fourier transform infra-red spectroscopy (FTIR), and changes in the mechanical properties of DPNR after immersion. The results of this research revealed that the presence of AN and ST can improve the mechanical properties of DPNR. They also showed that an increase in the concentration of AN decreased the swelling and increased the shrinking of rubber. However, an increase in the concentration of ST was found to increase the swelling and decrease the shrinking of rubber. From the results of the FTIR spectrum, DPNR was indicated to be more degraded compared to DPNR-gPAN/PS after immersion with DME. The surface morphology test, which was carried out with a scanning electron microscope (SEM), showed that DPNR-g-PAN/PS experienced a slight shrinking effect in its morphology while DPNR underwent a huge shrinking effect.
\end{abstract}

Keywords: Acrylonitrile; Deproteinized natural rubber; Dimethyl ether; Styrene

\section{Introduction}

Dimethyl ether (DME) is an alternative fuel with several advantages over other fuels, such as higher oxygen content, a higher cetane number than diesel oil, and a low boiling point. It is also non-toxic, non-teratogenic, non-mutagenic, and non-carcinogenic (Semelsberger et al., 2006; Arcoumanis et al., 2008; Li and Zhou, 2008). However, its chemical properties are different from those of LPG, which has moderate polarity and high gas permeability to organic compounds such as plastics and rubber; DME swells easily

* Corresponding author's email: ty_indahsari@yahoo.co.id; tutiindahsari@ft.unsri.ac.id; Tel.: +62-81282466080 doi: 10.14716/ijtech.v11i1.1942 
and dissolves organic compounds (Nishimoto, 2011). It can also attack some sealing dissolves organic compounds (Nishimoto, 2011). It can also attack some sealing materials and plastic components because of its low viscosity (Arcoumanis et al., 2008). Previous studies have made use of the immersion method through the use of swelling and mechanical properties as parameters to test for resistance in DME (Li and Zhou, 2008; Wu et al., 2008; Saputra et al., 2016; Sari et al., 2017; Saputra et al., 2018). According to research conducted by Li and Zhou (2008), immersion of rubber in a mixture of DME/diesel at 20/80 w/w produces a corroded rubber seal.

Furthermore, natural rubber grafted with acrylonitrile (AN) and styrene (ST) has the potential to be used as a seal for the storage of DME. It has excellent properties such as good elasticity, high tensile strength (TS), and good adhesion to metal. Polyacrylonitrile (PAN) is a non-solvent material with hydrocarbons, chlorinated hydrocarbons ketones, diethyl ether, and acetonitrile (Mark, 2009). The presence of PAN could increases its insolubility and resistance to organic solvents (Nataraj et al., 2012). ST has also been observed to be a good co-monomer for the stability of the graft-copolymerization process (Prasassarakich et al., 2001; Angnanon et al., 2011; Sari et al., 2015). According to studies conducted by Prasassarakich et al. (2001), the oil and solvent resistance of Natural Rubber can be improved by graft copolymerization using AN. Increases in TS and oil resistance were observed with an increase in the percentage grafting efficiency (GE) of AN monomer (Prukkaewkanjana et al., 2014); these results were also reported by Angnanon et al. (2011).

The objective of the present study was to obtain a copolymer of DPNR-g-PAN/PS with a high resistance to DME gas. This is important because resistance is the potency needed by natural rubber to survive the diffusion or corrosion caused by the DME. According to research conducted by Sari et al. (2017), the copolymer is expected to reduce the degradation of rubber because of the action of DME. The characteristics of the copolymer were determined using Fourier transform infrared spectroscopy (FTIR). The mechanical properties measured included TS, elongation at break (EB), and hardness, while the resistance test parameters included swelling, shrinking, and changes in mechanical properties after immersion. A surface morphology test was also performed using a scanning electron microscope (SEM) analysis.

\section{Methods}

\subsection{Materials}

The materials used in the present study included natural rubber latex with a high level of stabilized ammonia containing about 59-60\% dry rubber content (DRC) from South Sumatera, Indonesia. AN monomer $(\geq 99 \%)$ and ST monomer $(\geq 99 \%)$ were purchased from Sigma-Aldrich (SGP). The emulsifier SDS ( 90\%), urea, $\mathrm{K}_{2} \mathrm{~S}_{2} \mathrm{O}_{8}$ ( $\geq 99 \%$ ), N,Ndimethylformamide (DMF), and methyl ethyl ketone (MEK) were purchased from Merck (Darmstadt, Germany). Nitrogen gas was purchased from PT Trijaya Gasesindo (INA). Zinc oxide ( $\mathrm{ZnO})$, stearic acid, 2-mercaptobenzothiazole/MBT, and sulfur were used in the production of vulcanized rubber. Dimethyl ether (DME) was purchased from PT Bumi Tanggerang, Banten (INA), while DPNR was prepared by mixing $0.1 \mathrm{wt} \%$ urea and $1 \mathrm{wt} \%$ SDS at room temperature for 60 minutes (Pukkate et al., 2008; Suksawad et al., 2011).

\subsection{Preparation of Copolymer DPNR-g-PAN/PS}

This study was conducted in a $1.3 \mathrm{~L}$ reactor glass equipped with a hot plate, a magnetic stirrer, and a nitrogen gas inlet. The DPNR, SDS (0.67 w/w\% rubber), and distilled water were first charged into a reactor glass with the use of $\mathrm{K}_{2} \mathrm{~S}_{2} \mathrm{O}_{8}$, an initiator with $1 \mathrm{wt} \%$ total monomers (Sahoo, 2019). Then, the reaction was continued for 6 hours. The gross grafted 
DPNR consisted of the graft copolymer DPNR-g-PAN/PS, free DPNR, PAN, and PS-free homopolymer, and it was synthesized using emulsion polymerization methods with a ratio of DPNR/Monomer are 65/35, 70/30, 75/25 w/w, and a ratio of AN/ST are 95/5, 92/8, $90 / 10,80 / 20 \mathrm{w} / \mathrm{w}$. For the purpose of calculating the GE, as shown in Equation 1, the free DPNR, PAN, and PS-free homopolymer were removed using Soxhlet extraction with petroleum ether, DMF, and MEK, respectively. GE is a parameter that is influenced by reaction variables such as DPNR/M ratio and AN/ST ratio.

$$
\% \mathrm{GE}=\frac{\text { weight of copolymer DPNR-g-PAN/PS }}{\text { weight of dry coagulan }} \times 100
$$

\subsection{Characterization}

The TS (MPa) and EB (\%) were measured using a Tensometer LLOYD 2000R according to the ASTM D.412-06ae2 standard. Hardness (Shore A) was measured using a durometer, and adequate steps were taken to ensure that this measurement complied with the ASTM D.2240-05 standard. The FTIR spectra of the DPNR and DPNR-g-PAN/PS were recorded in solid states using a Nicolet iS5 spectrometer (Thermo Scientific) between 500 and $4000 \mathrm{~cm}^{-}$ 1. The scanning electron microscope (SEM) model type ZEISS EVO 50 was used to analyze the surface morphology of DPNR and DPNR-g-PAN/PS before and after immersion.

\subsection{Swelling and Shrinking Test}

The rubber to be vulcanized was immersed in liquid-phase DME in a $1.3 \mathrm{~L}$ pressure vessel. The changes in the masses of these samples were investigated after the samples had been immersed for several days and exposed to the atmosphere for 24 hours (Wu et al., 2008). Swelling was measured as a percentage (\%), as shown in Equation 2 (Li and Zhou, 2008; Hinchiranan et al., 2013).

$$
\text { Swelling/Shrinking }(\%)=\frac{\left(\mathrm{M}_{2}-\mathrm{M}_{1}\right)}{\mathrm{M}_{1}} \times 100 \%
$$

where $M_{1}$ is the mass of the sample before immersion and $M_{2}$ is the mass after immersion. The samples were referred to as wet samples after they had been immersed and were called dry samples after being exposed to the atmosphere for 24 hours.

\section{Results and Discussion}

\subsection{Grafting Characteristics}

The grafting characteristics of the DPNR-g-PAN/PS are shown by FTIR spectrum, GE, and mechanical properties. Figure 1a shows a comparison between the FTIR spectrum of DPNR (2) and that of the grafted copolymers (1); the $\mathrm{C} \equiv \mathrm{N}$ group shown at wave number $2,242.75 \mathrm{~cm}^{-1}$ indicated PAN grafted on a natural rubber chain, while the presence of benzene groups shown at wave number $705.16 \mathrm{~cm}^{-1}$ indicated PS grafted on natural rubber. The spectrum shown in Figure 1a is based on previous research by Sari et al. (2017). A nitrile group $(\mathrm{C} \equiv \mathrm{N})$ could be indicated at wave numbers $2,240-2,260 \mathrm{~cm}^{-1}$ (Smith, 1979) and at wave number $2,242 \mathrm{~cm}^{-1}$ (Nacimiento et al., 2012). In a previous study, Luo and Wu (2012) reported that a functional group the benzene ring at the wave number 701 and 760 $\mathrm{cm}^{-1}$. Figure $1 \mathrm{~b}$ shows the FTIR spectrum can evidence that AN and ST are grafted onto DPNR to form DPNR-g-PAN/PS, however the effect of varying composition AN/ST can not clearly observed. 


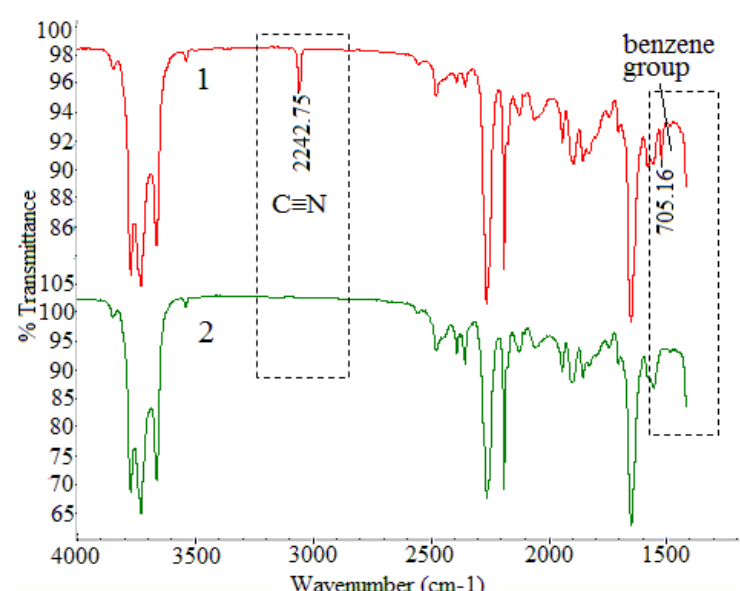

(a)

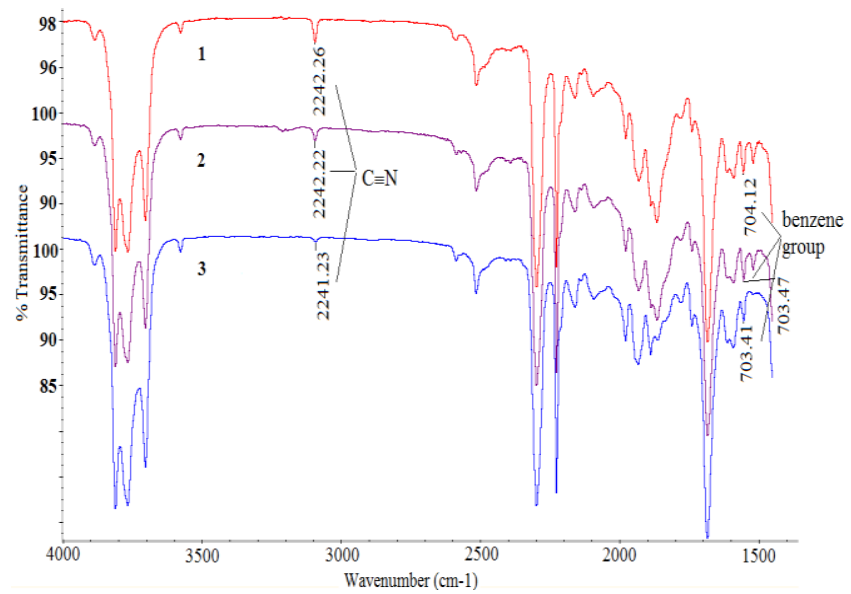

(b)

Figure 1 (a) FTIR spectrum of: (1) DPNR; (2) DPNR-g-PAN/PS. (b) FTIR spectrum of DPNR-gPAN/PS with varying composition of AN/ST: (1) 95/5; (2) 90/10; (3) 80/20

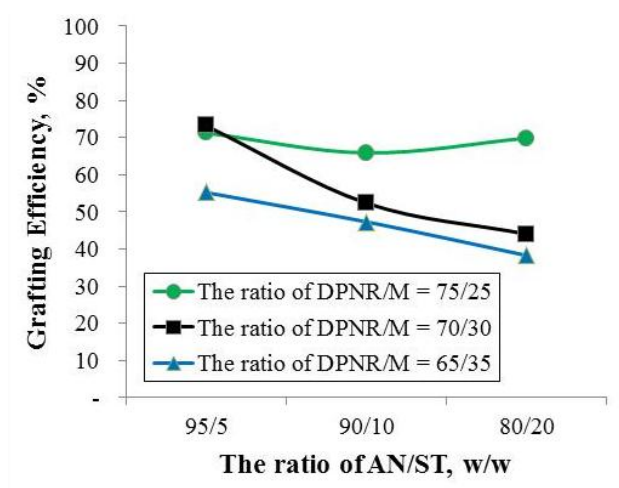

Figure 2 Grafting efficiency (GE) with the ratios of DPNR/M and AN/ST

Figure 2 observes the effect of the DPNR/M ratio on GE. It shows that decreasing the composition of DPNR in the ratio DPNR/M will be decreasing percentage of GE. Similarly, the decreasing the composition of AN in the ratio of AN/ST decreace the percentage of GE. This indicates immiscibility between the AN and ST molecules. Therefore, it is possible that grafting copolymerization occurs only on the surfaces of latex particles. It was also found that the continuous addition of monomers AN and ST does not increase the percentage of GE; however, most free polymers were formed (Wongthong et al., 2013).

\subsection{Mechanical Properties of Vulcanized DPNR and DPNR-g-PAN/PS}

The mechanical properties of the vulcanized copolymers were represented by TS, EB, and hardness. Figure 3a shows that TS was higher in DPNR-g-PAN/PS copolymers than in DPNR and that increasing concentration of the total monomers increased the TS. However, PAN and polystyrene (PS), as free polymers, can also function as fillers to reinforce the mixture, thus increasing the TS. TS is inversely proportional to EB, which decreases with PAN and PS. Therefore, the decreased value of EB was not particularly significant. It can be concluded from these results that the presence of PAN and PS as free polymers makes vulcanized rubber slightly rigid because they cover most of its pores. 


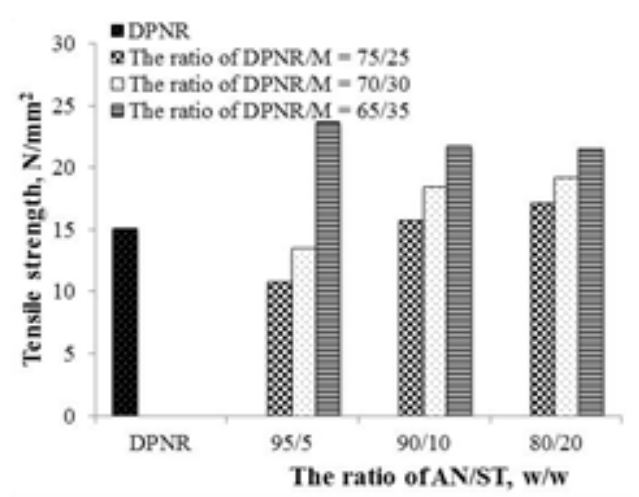

(a)

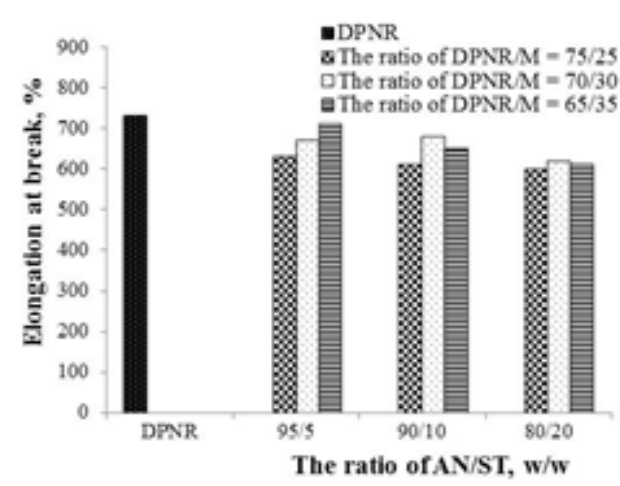

(b)

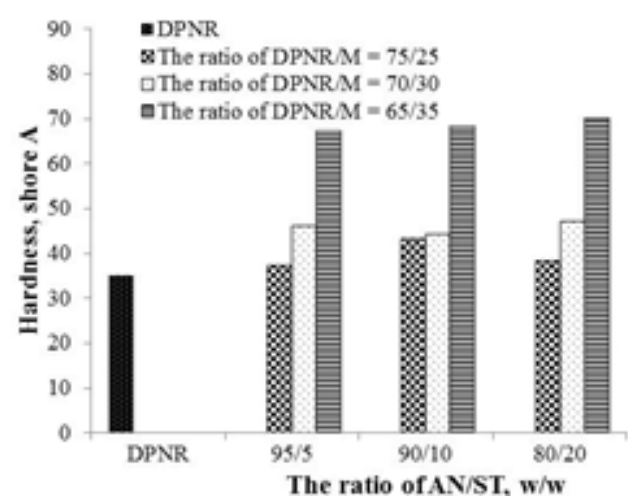

(c)

Figure 3 The influence of AN/ST monomer concentration on: (a) tensile strength; (b) elongation at break; and (c) hardness of vulcanized DPNR-g-PAN/PS

The mechanical properties of grafted, vulcanized rubber are influenced by the properties of the grafted polymers. The hardness of the polymer affects the flexibility of the rubber material, and this concept also applies to the types and molecular weights of the polymers (Mark et al., 2013). PAN, a fiber polymer, is hard and has a high molecular weight, while PS, a plastic polymer, is softer. Grafting PAN onto a natural rubber can increase the rubber's TS and hardness (George et al., 2007; Prukkaewkanjana et al., 2014). Figure 3a shows that decreasing AN concentration increases TS, while Figure $3 b$ reveals that EB decreases with an increase in ST concentration.

Several previous studies have discussed the process of grafting AN onto natural rubber. For example, a study by Angnanon et al. (2011) reported that NR-g-AN/ST functioned as a compatibility material in the process of blending natural rubber with NBR. In Figure 3, the presence of copolymer grafting increased the TS, but the varying composition of AN/ST did not significantly affect the vulcanized TS. Another study, conducted by George et al. (2007), stated that an increase in the concentration of AN in the copolymerization process increases the TS and decreases the EB. Similarly, a study carried out by Prukkaewkanjana et al. (2014) revealed that the TS of DPNR-graft-PAN increased along with increasingly efficient AN grafting. In addition, DPNR-graft-PAN has a dipole-dipole interaction between its nitrile groups. Therefore, a decrease in the PAN content of rubber increases the rigidity of the graft copolymer (Prukkaewkanjana et al., 2014). The use of PAN and PS as either grafted or free polymers in vulcanized rubber improves hardness. Figure $3 \mathrm{c}$ shows that an increase in the concentration of total monomers increases hardness. 


\subsection{Swelling and Shrinking Test on DPNR and DPNR-g-PAN/PS in DME}

The change in the mass of the wet sample indicated swelling in DPNR and DPNR-gPAN/PS, as shown in Figure 4a. This figure also shows that the decrease in the swelling of DPNR-g-PAN/PS occurred in all AN/ST concentration ratios, as opposed to that of DPNR, and that the increasing concentration of ST increased swelling. The lowest swelling $23.14 \%$ is attained at the ratio of DPNR/M $=65 / 35$ with the composition of the monomer AN $/ \mathrm{ST}=$ $95 / 5$. Figure $4 \mathrm{~b}$ shows the change in the mass of the dry sample after 24 hours. This figure indicates that the mass decreased after seven days of immersion in DME. The Figures $4 \mathrm{a}$ and $4 \mathrm{~b}$ show that the ratio DPNR/M $=65 / 35$ attains the lowest percentage of swelling and shrinking. However, the lowest percent swelling was attain with the composition of AN/ST $=95 / 5$, while the lowest percent of shrinking was attain at the composition of AN $/ \mathrm{ST}=$ $80 / 20$. This condition requires the advance optimization of the AN/ST composition for swelling and shrinking test.

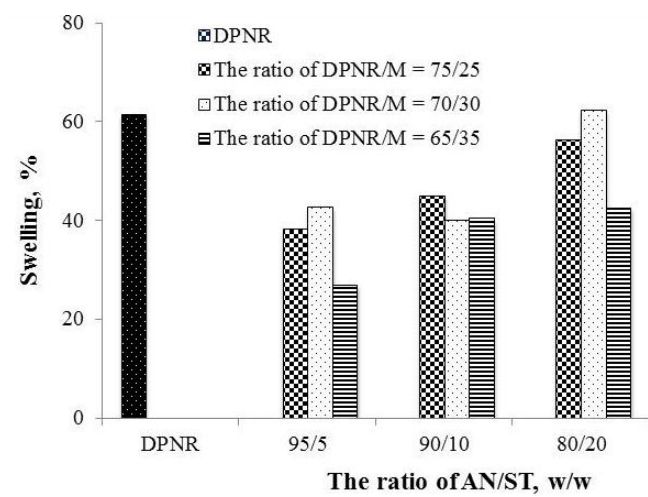

(a)

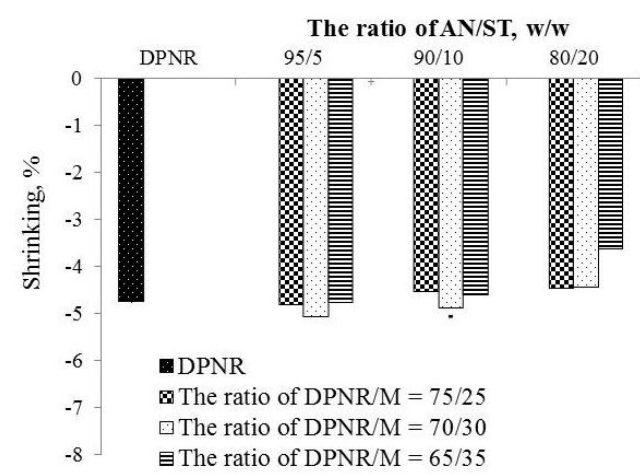

(b)

Figure 4 The swelling and shrinking of DPNR and DPNR-g-PAN/PS after immersion in DME for 168 hours: (a) wet sample; (b) dry sample

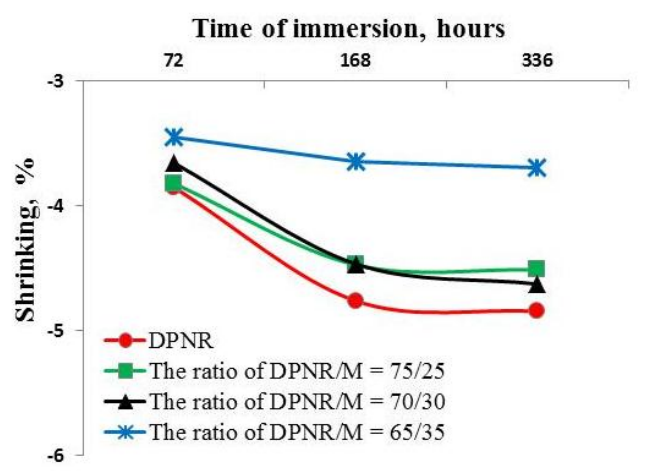

Figure 5 The mass degradation of DPNR-g-PAN/PS after immersion in DME (dry measurement) at an AN/ST ratio of $80 / 20$

Figure 5 shows that all DPNR and DPNR-g-PAN/PS samples lost some mass. This means that increasing ST concentration decreases the loss of mass. The lowest mass $(-3.64 \%)$ was recorded at an AN/ST ratio of 80/20 and a DPNR/M ratio of 65/35. The smallest decrease in mass shown in Figure 5 could be attributed to the presence of PAN and PS as a free homopolymer. At the ratio DPNR/M = 65/35, PAN and PS homopolymer formation is more than other ratios. This phenomenon of free polymers provides filler for the crosslinked rubber. As shown by Saputra et al. (2016), increased loading in rubber filler decreases the loss of mass. Previous researchers, such as Mikhailova et al. (2009), have investigated the 
increase in filler composition and found that it inhibits absorption and reaction in vulcanized rubber. Likewise, Muniandy et al. (2012) found that filler loading results in greater interaction between the rubber and the filler. Therefore, a higher level of interaction between the filler and the rubber matrix corresponds to a lower swelling value. The shrinking of mass, as shown in Figure 5, reveals the vulcanized rubber degradation caused by DME.

\subsection{Chemical and Physical Properties After Immersion}

Figure 6 shows the spectrum of DPNR and DPNR-g-PAN/PS before and after immersion in DME. In the DPNR spectrum after immersion, group $\mathrm{C}=\mathrm{C}$ double bonds were lost at wave number $1576.59 \mathrm{~cm}^{-1}$. These bonds might have been broken, changed into $\mathrm{C}-\mathrm{C}$ at a wave number between $1000 \mathrm{~cm}^{-1}$ and $700 \mathrm{~cm}^{-1}$, and changed into $\mathrm{C}-\mathrm{H}$ at $669.35 \mathrm{~cm}^{-1}$. This could have been a result of interaction with DME. Figures $6 \mathrm{c}$ and $6 \mathrm{~d}$ depict a comparison of the DPNR-g-PAN/PS spectrum before and after immersion. It was discovered that the spectrums Figures $6 \mathrm{c}$ and $6 \mathrm{~d}$ had slightly broken $\mathrm{C}=\mathrm{C}$ double bonds, the changed of $\mathrm{C} \equiv \mathrm{N}$ group from wave number $2242.57 \mathrm{~cm}^{-1}$ to wave number $2242.27 \mathrm{~cm}^{-1}$, and a benzene ring functional group from wave number $703.95 \mathrm{~cm}^{-1}$ to wave number $702.72 \mathrm{~cm}^{-1}$. This was probably caused by the interaction of DME with PAN, PS, and DPNR as a free polymer. The comparison shows that DPNR degraded more than DPNR-g-PAN/PS.

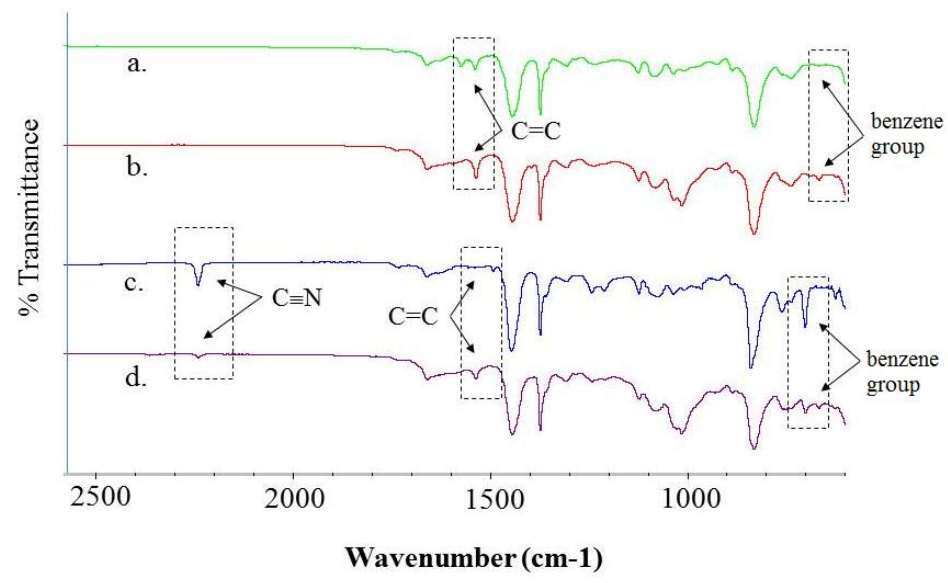

Figure 6 The FTIR spectrum of: (a) DPNR before immersion; (b) DPNR after immersion; (c) DPNRg-PAN/PS before immersion; and (d) DPNR-g-PAN/PS after immersion

The deviation in TS is as shown in Figure 7a. The FTIR spectrum in this figure showed that the breaking of $\mathrm{C}=\mathrm{C}$ double bonds to $\mathrm{C}-\mathrm{C}$ and $\mathrm{C}-\mathrm{H}$ can also reduce the strength and elasticity of the rubber. Therefore, TS and EB generally decrease, as shown in Figures 7a and 7c. Figure $7 \mathrm{~b}$ shows that the TS of DPNR-g-PAN/PS was generally higher than that of DPNR except for the AN/ST 80/20 ratio. It can be concluded that the relatively high TS of the dispersed DPNR was surrounded by the PAN phase, which made it function as an oilresistant compound and therefore restrained its swelling. However, in the ratio AN $/ \mathrm{ST}=$ $80 / 20$, there more PS than other ratio, therefore the resistance to swelling decreases. This causes an increase in swelling and decreases relative TS. Figure $7 \mathrm{~d}$ shows that hardness increased after immersion and that the occurrence of swelling and shrinking caused a reduction in some of the material contained in the rubber. Therefore, the sol fraction decreased and the rubber became denser, causing an increase in the hardness of the material. 
Degradation of its Mechanical Properties by Dimethyl Ether

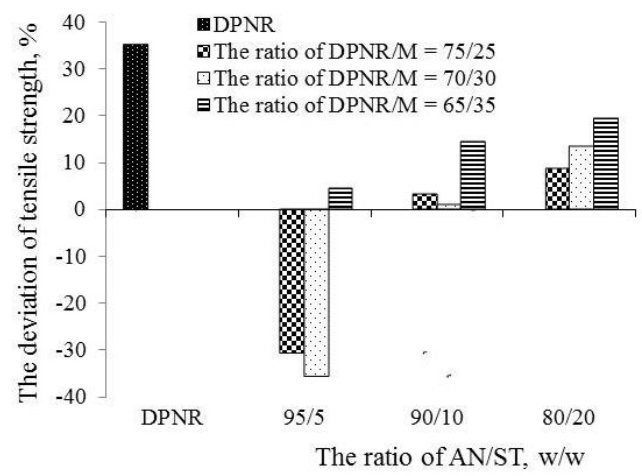

(a)

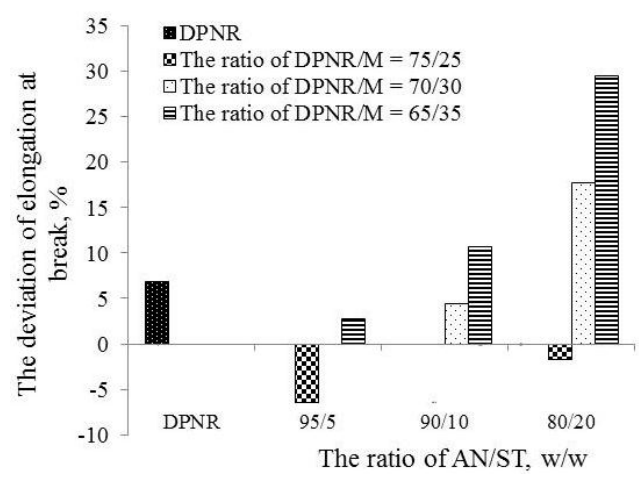

(c)

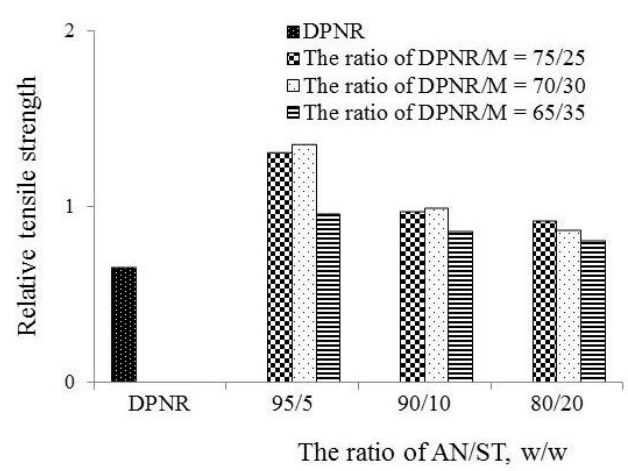

(b)

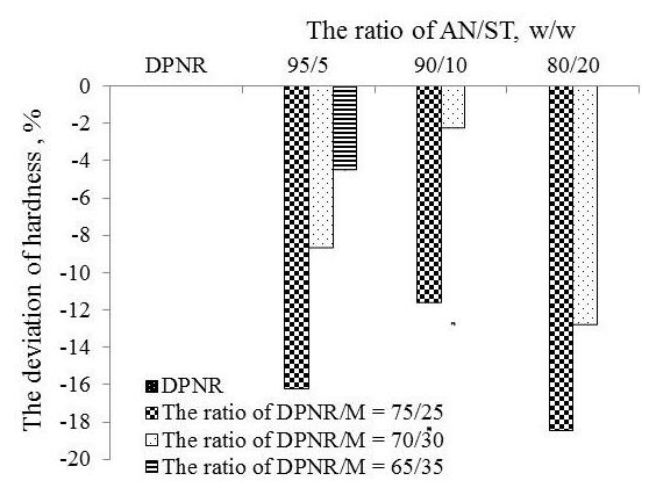

(d)

Figure 7 The deviation of mechanical properties after immersion in DME: (a) tensile strength; (b) relative tensile strength; (c) elongation at break; (d) hardness

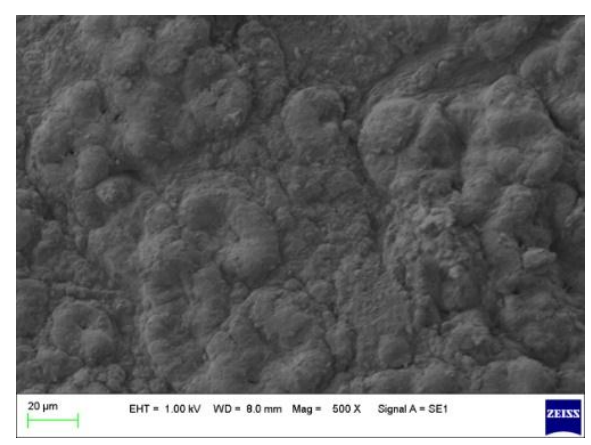

(a)

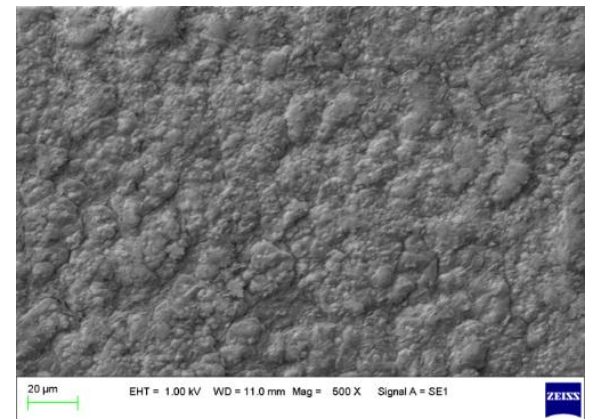

(c)

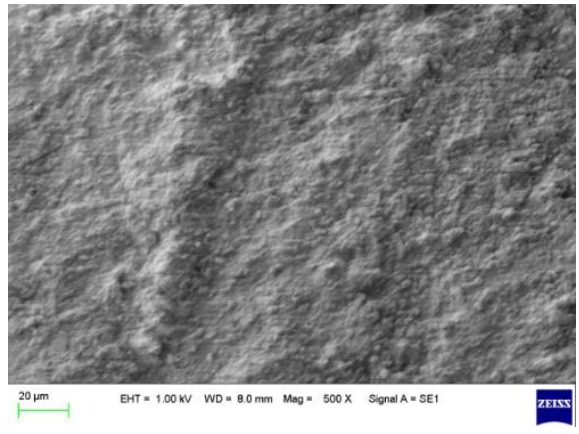

(b)

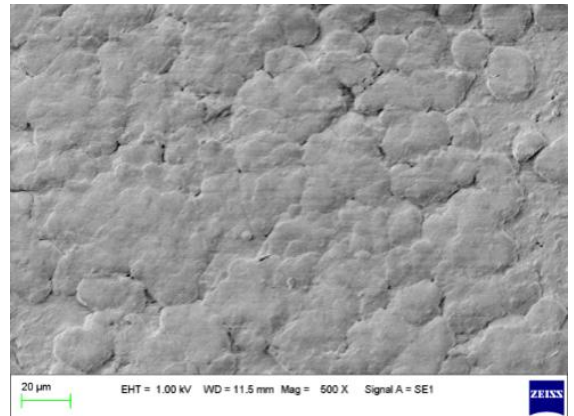

(d)

Figure 8 The surface morphology of DPNR and DPNR-g-PAN/PS as shown by SEM analysis before and after immersion in DME: (a) vulcanized DPNR before immersion; (b) vulcanized DPNR after

A surface morphology analysis was measured with SEM model type ZEISS EVO 50 at 500 times magnification to characterize the degradation behavior of DPNR and DPNR-g- 
PAN/PS before and after immersion in DME. Figures $8 \mathrm{a}$ and $8 \mathrm{~b}$ show a difference between the surface morphology of vulcanized DPNR. Figure $8 \mathrm{~b}$ shows that the erosion of the material (shrinking) was a result of the absorption and desorption of DME into the rubber network. This can be attributed to a possible reaction between DME and some ingredients like as $\mathrm{ZnO}$, stearic acid, MBT or sulfur during its absorption into the rubber. This phenomenon is also shown in Figures 8c and 8d. In Figure 8d, shrinking resulted in morphological changes that cannot be seen in Figure 8c. The surface of Figure 8d was smooth, flat, and sallow in color. The Figures $8 \mathrm{a}, 8 \mathrm{~b}, 8 \mathrm{c}$ and $8 \mathrm{~d}$ reveals that the morphology of DPNR-g-PAN/PS experienced a slight shrinking effect while that of DPNR underwent a huge shrinking effect. In a comparison SEM analysis, Saputra et al. (2018) concluded that the filler can prevent DME diffusion. As a matter of fact, the PAN and PS can act as a filler thats can prevent DME diffusion.

\section{Conclusions}

The present study focused on the production and resistance testing of a DPNR-gPAN/PS copolymer in DME with the influence of AN monomer and ST monomer. The presence of AN and ST increases the mechanical properties of DPNR and DPNR-g-PAN/PS. It was found that the lowest percent swelling was attain with the highest of composition of AN, while the lowest percent of shrinking was attain at the highest of composition of ST. This condition requires the advance optimization of the AN/ST composition for swelling and shrinking test. The FTIR spectrum of DPNR degraded more than that of DPNR-gPAN/PS spectrum and the morphology of DPNR-g-PAN/PS experienced a slight shrinking effect while that of DPNR underwent a huge shrinking effect.

\section{Acknowledgments}

The authors wish to express their gratitude to the Research Laboratory of Chemical Engineering FT-UI and the Rubber Research Center Bogor for their support in this research.

\section{References}

Angnanon, S., Prasassarakich, P., Hinchiranan, N., 2011. Styrene/Acrylonitrile Graft Natural Rubber as Compatibilizer in Rubber Blends. Polymer-Plastics Technology and Engineering, Volume 50(11), pp. 1170-1178

Arcoumanis, C., Bae, C., Crookes, R., Kinoshita, E., 2008. The Potential of Di-methyl Ether (DME) as an Alternative Fuel for Compression-ignition Engines: A Review. Fuel, Volume 87(7), pp. 1014-1030

George, B., Maiti, S.N., Varma, I.K., 2007. Impact Modification of SAN using NR-g-SAN Copolymers. Journal of Materials Science, Volume 42(19), pp. 8262-8270

Hinchiranan, N., Wannako, P., Paosawatyanyong, B., Prasassarakich, P., 2013. 2,2,2Trifluoroethyl Methacrylate-graft-natural Rubber: Synthesis and Application as Compatibilizer in Natural Rubber/Fluoroelastomer Blends. Materials Chemistry and Physics, Volume 139(2-3), pp. 689-698

Li, G.B., Zhou, L.B., 2008. Experimental Research on the Resistance of Rubber Materials to Dimethyl Ether. In: Proceedings of the Institution of Mechanical Engineers, Part D: Journal of Automobile Engineering, Volume 222(6), pp. 975-978

Luo, P., Wu, G., 2012. Thermo-mechanical Degradation-induced Grafting of Poly (styreneacrylonitrile) to Chlorinated Polyethylene. Polymer Degradation and Stability, Volume 97(5), pp. 766-770 
Mark, J.E., 2009. Polymer Data Handbook. Volume 27, New York, USA: Oxford University Press

Mark, J.E., Erman, B., Roland, C.M., 2013. The Science and Technology of Rubber. $4^{\text {th }}$ Edition, Boston, Massachusetts, USA: Academic Press

Mikhailova, G.A., Baburina, V.A., Kalmykova, V.Y., Deberdeev, R.Y., Kutyrev, G.A., 2009. Effect of Sorption-inactive Fillers on the Oil and Petrol Resistance of Siloxane Rubbers. International Polymer Science and Technology, Volume 36(4), pp. 19-22

Muniandy, K., Ismail, H., Othman, N., 2012. Effects of Partial Replacement of Rattan Powder by Commercial Fillers on the Properties of Natural Rubber Composites. BioResources, Volume 7(4), pp. 4640-4657

Nacimiento, F., Alcántara, R., González, J.R., Tirado, J.L., 2012. Electrodeposited Polyacrylonitrile and Cobalt-Tin Composite Thin Film on Titanium Substrate. Journal of The Electrochemical Society, Volume 159(7), pp. A1028-A1033

Nataraj, S.K., Yang, K.S., Aminabhavi, T.M., 2012. Polyacrylonitrile-based Nanofibers-A State-of-the-Art Review. Progress in Polymer Science, Volume 37(3), pp. 487-513

Nishimoto, K., Yamamoto, M., Omura, A., Sawada, T., Toyota, A., 2011. Dimethyl EtherResistant Rubber Composition. European Patent office, Number EP2348069A1, pp. 110

Prasassarakich, P., Sintoorahat, P., Wongwisetsirikul, N., 2001. Enhanced Graft Copolymerization of Styrene and Acrylonitrile onto Natural Rubber. Journal of Chemical Engineering of Japan, Volume 34(2), pp. 249-253

Prukkaewkanjana, K., Kawahara, S., Sakdapipanich, J., 2014. Influence of Reaction Conditions on the Properties of Nano-matrix Structure Formed by GraftCopolymerization of Acrylonitrile onto Natural Rubber. Advanced Materials Research, Volume 844, pp. 365-368

Pukkate, N., Yamamoto, Y., Kawahara, S., 2008. Mechanism of Graft Copolymerization of Styrene onto Deproteinized Natural Rubber. Colloid and Polymer Science, Volume 286(4), pp. 411-416

Sahoo, G., Sarkar, N., Swain, S.K., 2019. Effect of Layered Graphene Oxide on the Structure and Properties of Bovine Serum Albumin Grafted Polyacrylonitrile Hybrid Bionanocomposites. Polymer Composites, Volume 40(10), pp. 3989-4003

Saputra, A.H., Johan, Sari, T.I., Cifriadi, A., Maspanger, D.R., Bismo, S., 2016. Degradation Characteristics of Vulcanized Natural Rubber by Dimethyl Ether Through Filler and Plasticizer Composition Variations. International Journal of Technology, Volume 7(4), pp. 616-624

Saputra, A.H., Juneva, S., Sari, T.I., Cifriadi, A., 2018. Degradation of Blending Vulcanized Natural Rubber and Nitril Rubber (NR/NBR) by Dimethyl Ether through Variation of Elastomer Ratio. In: IOP Conference Series: Materials Science and Engineering, Volume 345(1), pp. 012035

Sari, T.I., Saputra, A.H., Bismo, S., Maspanger, D.R., Cifriadi, A., 2015. The Effect of Styrene Monomer in the Graft Copolymerization of Acrylonitrile onto Deproteinized Natural Rubber. International Journal of Technology, Volume 6(7), pp. 1164-1173

Sari, T.I., Saputra, A. H., Maspanger, D.R., Bismo, S., 2017. Modification of Natural Rubber as a Resistant Material to Dimethyl Ether. Journal of Applied Sciences, Volume 17(2), pp. $53-60$

Semelsberger, T.A., Borup, R.L., Greene, H.L., 2006. Dimethyl Ether (DME) as an Alternative Fuel. Journal of Power Sources, Volume 156(2), pp. 497-511

Smith, A.L., 1979. Applied Infrared Spectroscopy: Fundamentals, Techniques, and Analytical Problem-Solving. Wiley, Hoboken, New Jersey, USA 
Suksawad, P., Yamamoto, Y., Kawahara, S., 2011. Preparation of Thermoplastic Elastomer from Natural Rubber Grafted with Polystyrene. European Polymer Journal, Volume 47(3), pp. 330-337

Wongthong, P., Nakason, C., Pan, Q., Rempel, G.L., Kiatkamjornwong, S., 2013. Modification of Deproteinized Natural Rubber via Grafting Polymerization with Maleic Anhydride. European Polymer Journal, Volume 49(12), pp. 4035-4046

$\mathrm{Wu}, \mathrm{N}$. , Zhang, W., Huang, Z., 2008. Impact of Dimethyl Ether on Engine Seal Materials. Frontiers of Energy and Power Engineering in China, Volume 2(3), pp. 279-284 